\title{
85277 - DOENÇA DE PARKINSON: PROPOSIÇÃO DE CARTILHA COM EXERCÍCIOS TERAPÊUTICOS
}

\author{
Pôster - Gerontologia
}

Anelise Ineu Figueiredo / Figueiredo, AI / PUCRS; Eliana da Silva Jacques / Jacques, ES / PUCRS; Matheus de Souza Urbanetto / Urbanetto, MS / PUCRS; Bianca Pacheco Loss / Loss, BP / PUCRS; André Zanluchi / Zanluchi, A / PUCRS; Régis Gemerasca Mestriner / Mestriner, RG / PUCRS

Introdução: A Doença de Parkinson (DP) é uma doença neurodegenerativa de progressão lenta, na qual ocorre degeneração dos neurônios dopaminérgicos da zona pars compacta da substância nigra mesencefálica. Clinicamente, a DP se caracteriza por tremor, rigidez, bradicinesia e alterações da postura, do equilíbrio, da mobilidade e marcha, alterações essas que resultam em dificuldades na realização das atividades de vida diária. Estudos têm demonstrado que programas de exercício físico regular são uma importante estratégia para melhorar o controle motor, o equilíbrio e a mobilidade funcional dessa população. Diferentes intervenções baseadas em movimento têm sido descritas na literatura para a DP, tais como: dança, caminhada nórdica, Tai Chi, realidade virtual e o método Pilates, dentre outros. O método Pilates envolve exercícios de alongamento e força muscular, de maneira ampla e lenta, auxiliando na recuperação e reorganização dos engramas e memória motora dos pacientes com DP. Por outro lado, sabe-se que existem diversos fatores limitadores para a participação dos pacientes com DP nessas terapias, tais como: as restrições financeiras, a dependência de familiar para acompanhar os atendimentos presenciais e/ou dificuldade de mobilidade para chegar até um serviço de saúde. Objetivo: Desenvolver uma cartilha de exercícios home based utilizando alguns princípios do método Pilates. Método: Realizou-se um estudo de revisão integrativa, visando o desenvolvimento de material didático (cartilha). Foram consultados os principais Guidelines existentes para tratamento fisioterapêutico na DP e do método Pilates. Após, foi realizada a criação do material com linguagem simplificada, além de possuir imagens com instruções de forma clara e acessível. Resultados: A partir da revisão, confeccionou-se uma cartilha com exercícios home based utilizando alguns princípios método Pilates. CONCLUSÃO: Esse material é um dos primeiros a propor exercícios terapêuticos utilizando os princípios do método Pilates para serem realizados no domicílio do indivíduo com DP. Espera-se com isso tornar o acesso aos exercícios mais fácil para todos os pacientes. Novos estudos com a finalidade de desenvolver estratégias em relação ao tratamento no âmbito domiciliar dos pacientes com DP são necessários, bem como a determinação da efetividade da presente cartilha.

Palavras-chave: doença de parkinson; técnicas de exercício e movimento; fisioterapia. 